\title{
NATURALIZATION: A NEW CONCEPT DEVELOPED AND CARRIED OUT IN THE SUBJECT "ENVIRONMENTAL TECHNOLOGY" OF DEGREE IN INDUSTRIAL ENGINEERING
}

\author{
L. Pozo ${ }^{1}$, J. Lebrato', D. Garvi ${ }^{1}$, B. Jigena², J.J. Muñoz ${ }^{2}$ \\ ${ }^{1}$ University of Seville (SPAIN) \\ ${ }^{2}$ University of Cádiz (SPAIN)
}

\begin{abstract}
Environmental Technology is a 6 credits transversal subject included in the curriculum of all the degrees in Industrial Engineering at the Higher Polytechnic School of the University of Seville. In the last 5 academic courses, the students of this matter have been working with the concept of "Naturalization". In the different topics which are studied in this subject, they have to apply the naturalization of the systems in order to use natural resources for improving processes. The Naturalization implies improvements in energetic efficiency, development of green spaces and $\mathrm{CO} 2$ capture and can be applied the majority of the industrial and urban activities. Some of the most meaningful results that our students have researched are:
\end{abstract}

i) Naturalization of a large pond in a business park in Jaen (Spain) performing its layout and eventually implementing it, using plants to improve water quality and stones for fix them and to give support for bacterial biofilms. The students have improved their skills not only in the increase of new knowledge but in the ability of work in groups and carry out a real project under different points of view.

ii) Project of naturalization of a neighbourhood in Seville, based on the increase of green spaces, with vegetal species which are able to capture electromagnetic radiations and $\mathrm{CO} 2$ emissions as well.

iii) Naturalization of the margins of one lagoon in a park in Seville, transforming the precast panelled walls in breakwater bed of stones planted with bank river plants in order to improve the water quality and the landscape.

Keywords: Naturalization, $\mathrm{CO}_{2}$, water quality, energy efficiency.

\section{INTRODUCTION}

Natural systems are controlled, or cyclic, so that a step-products are the raw materials of the following, the processes occur to compensate all the arising effects in each case.

Natural resources are recycled one by one, without exception, so that the land can take years, millennia, millions of years, cycling and cycling generations of all life forms that inhabit the planet.

Artificial systems, with human influence, are random in many cases, and therefore have erratic and unpredictable long-term consequences, hence it's necessary to establish systematic process control routines / Naturalization to close the cycles of life.

The ultimate aim is both to improve the performance of processes of production and to preserve life as we know it on Earth, in what must be the principle of all environmental performance that maintains at the same time industrial activity and the natural cycles within stable behaviour margins that ensure the diversity of all species.

As far as we're concerned Environmental Technology should attempt to compensate human actions on the environment by closing the cycles of life in respect to human development, biodiversity of species and natural systems and not design random processes, which may introduce new medium/long term instability factors.

For this we must learn from nature and design actions that foster the development of disturbed systems to naturalized systems that support human activity and, moreover, do so within a reasonable period of time for us, nature isn't in a hurry not like human beings. We call these high speed natural systems, HSNS. 


\section{NATURALIZATION AND ENERGETIC EFFICIENCY}

Nature works in closed loop systems, or automatic control, which take information from the very process and act accordingly, based on a prior objective introduced in the control tool.

Automatic control is a problem of:

1 Sensing the process and transmit signals to and from the process.

2 Regulation: preparation of orders from certain system data.

- Compare the input (current system) with the output (naturalized system)

- Act accordingly, meaning to send an order to the actuator.

3 Run the order of work of the controller.

A typical control loop is formed by the process, the sensor, the transmitter, the controller and the actuator.

The controller allows the process to meet its goal of transforming the material and performs two essential functions:

- Compare the measured variable with the referenced one or desired one (setpoint) to determine the error.

- Stabilizes the dynamic performance of the control loop by sending an order to the actuator to reduce or eliminate the error.

- It seeks to COMPENSATE the negative impacts that occur in processes with actions that foster an improvement and change towards an integral climate system, ICS.

- The feasibility of ICS is based on achieving short, medium and long term economic positive balances of the different actions proposed, so that easily enables its implementation.

- The basis of this proposal is given by the recognition that nature is the least "spender" in managing living systems. Large and small clusters of species in various areas, with all kinds of specifications are managed by Mother Earth WITH THE LOWEST COSTS POSSIBLE, assumed in all cases the energy the sun sends us every day.

- The project creates a plan of actions or "patterns" to follow to achieve the $\mathrm{CO}_{2}$ balance $=0$, which includes activities that may already be taking place, such as energy efficiency of the facilities, with the gradual naturalization of processes which increase ecological diversity, with a management of resources and waste in closed cycles that generate, at the same time, nearby local development.

Our group has empirically established the following equation in the subject of Environmental Technology:

The limit of the process' costs, when naturalization tends to infinity, tends to zero.

Therefore it has been developed the integral climate system, ICS, which is one that, naturalizing processes progressively, limits adverse effects on the surrounding environment and decreases the final rate of $\mathrm{CO}_{2}$ emission into the atmosphere until achieved, at least, a $\mathrm{CO}_{2}$ balance zero.

Energetic efficiency:

- Point 1 = Energy saving.

- Point 2 = Energy production.

Naturalization efficiency:

- Point $3=\mathrm{CO}_{2}$ capture.

- Point $4=$ Increase of biodiversity.

Management of resources and wastes efficiency:

- Point $5=$ Optimizing the management of resources and waste.

Social and cultural efficiency:

- Point $6=$ Local and professional possible development . 
- Point 7 = Recovery of the culture of the community

It is ultimately the implementation of all the points previously seen to reach an INTEGRAL CLIMATE SYSTEM, ICS, whose $\mathrm{CO}_{2}$ balance is continuously minimized over time.

To set up what we call "Integral Climate System" is essential to contemplate the fundamental interactions present in any environmental system: fauna, flora, geology and microclimate. Starting from subsystems such as economic, religious, social, cultural and psychological will ease to achieve naturalization.

A study must be conducted regarding implementation and operation management of the "Integral Climate System". Environmental aspects, legal requirements and regulations will be taken into account, as well as objectives and targets to be met for its planning.

\section{ENVIRONMENTAL TECHNOLOGY SUBJECT}

In the optative transverse subject of Environmental Technology ${ }^{1}$ of the fourth year of the degree in chemical, mechanical, electronic and industrial design engineering at the Polytechnic School of the University of Seville are theoretically introduced these new concepts and their application in solving real problems carried out by our group Tar of water and environmental engineering in different environments. The subject has six ECTS credits, half of them are theoretical and the other half practical.

In general we can say that the work of the subject in each school year is based on the actual resolution of the problems that appear in urban naturalization.

- City Without $\mathrm{CO}_{2}$ : conversion of $\mathrm{CO}_{2}$ producers NEIGHBOURHOODS into NEIGHBOURHOODS whose $\mathrm{CO}_{2}$ balance is minimized continuously, carrying out actions that are sustainable from an economic and social perspective, and that generate lasting environmental improvements over time.

It's proposed an experience in a pilot neighbourhood, which will set the guidelines to be followed in a near future neighbourhood to neighbourhood to end up in an ALIVE CITY Without $\mathrm{CO}_{2}$ based on the following lines of action:

- Energetic efficiency: it's established a quality mark of energetic efficiency in the neighbourhood, at a municipal level, that marks the decrease of total energy spent in the neighbourhood, including public facilities and homes, compared to previous consumption for the same purpose.

Workshops are held in the neighbourhood's community centers to train citizens and municipal officers in the proposed objectives.

- Naturalization: A first step to achieve the viability of the project is to value the proposed changes that generate $\mathrm{CO}_{2}$ capture, as fundable activity in national and European programs in the environment of the Kyoto Protocol, which compels our country, and the rest of European countries to reduce its contribution of " $\mathrm{CO}_{2}$ country".

- Green Urban Mesh: it is proposed a mesh green corridors infrastructure to improve citizen connectivity, recovering old urban elements such as walks, boulevards and avenues with trees, where it's easier to enhance the "walkability" of public spaces and improve the quality of the urban environment and the life of people.

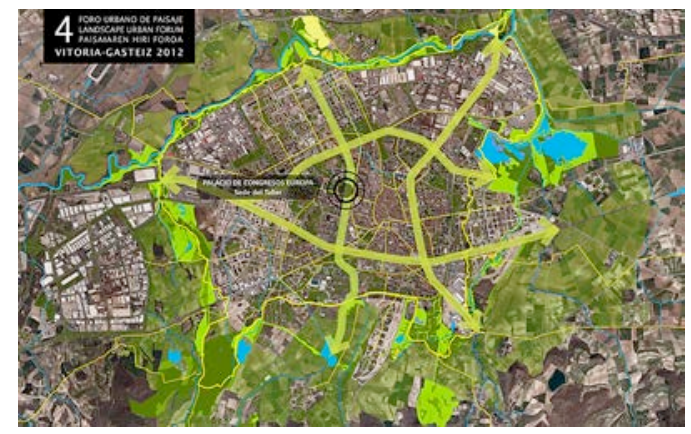

Figure 1.- Visual example of Green Urban Mesh. 
- Backyards and gardens in the neighbourhood: it's proposed a measurement of reforestation and revegetation with native trees and bushes that capture a large amount of $\mathrm{CO}_{2}$ with little irrigation requirements, applying knowledge of xeriscape.

- Forest Area Without $\mathrm{CO}_{2}$ Project: Based on spots and green corridors that converge in parks and not urbanized spaces that continuously enhance forest biomass in a harmonious and sustainable manner.

- Naturalization of ponds and urban wetlands: it's a new concept in low-cost maintenance of urban wetlands, to prevent eutroficity. Their naturalization is proposed by implanting ripraps where marsh plants are installed between the rocks on the concrete shore. This riprap will also work as wildlife shelter and balancing the existing ecosystem. In addition, the visual and scenic component will be improved giving a more natural appearance and attractive to the pond.

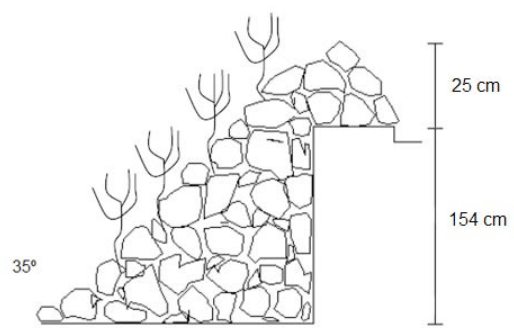

Figure 2.- Riprap's profile.

- Using resources and recovering resources of waste: Recovery of rainwater in public buildings and in the municipality in order to be used for irrigation of green areas, street cleaning, designing collecting gutters effectively and getting its orderly evacuation to the objectives.

- Local development, social intervention, employment generation and knowledge: The dynamics of the neighbourhood Without $\mathrm{CO}_{2}$ allows a series of actions that engage and create economy to the whole neighbourhood depending on its age and possibilities.

1 The school garden centre: it's proposed to use part of the reforested area to locate a small forest garden centre school, which can work as a supply for successive replantings and that promotes environmental education and awareness.

2 Employment workshop and forestry training, City Without $\mathrm{CO}_{2}$ : in order to cover the tasks of site preparation, reforestation and subsequent maintenance as well as improve the skills and / or recycling of young people and people at risk of labor and social exclusion.

3 Participatory reforestation: If the previous workshop is coordinated with the reforestation of the neighbourhood, career and working opportunities in cooperatives or social enterprises in the neighbourhood will be created.

In addition to this, some citizen reforestation days will be organized which will invite interested people and social collectives of the neighbourhood to participate which will allow the development of relations between the project and its immediate surroundings.

- The urban vegetable patches: it provides the neighbourhood with vegetable patches in public spaces as a means of improving household economy, harmonize the free time of the elderly and education of children in natural values, in an intergenerational community work space.

- Reduction of the high-carbon footprint: it's a measure for the local government to encourage the production and exchange of products generated in the neighbourhood, both in the food sector and the craft and the recovery of ancient professions.

In parallel, the neighbourhood's trade is stimulated so that it has a higher amount of own products itself or nearby towns thus reducing the carbon footprint of these products. All this leads to the development of an ECOLOGICAL NEIGHBOURHOOD MARKET that supports these local development incentives nearby. 


\section{CONCLUSION}

The project's goal is to create a "guide" of actions so that the city has in its hands a broad view of the lines to follow in order to become a Without $\mathrm{CO}_{2}$ town, how to finance the process and how to value the benefits of turning the municipality into a INTEGRATED CLIMATE SYSTEM.

\section{REFERENCES}

[1] www.aguapedia.org 